balf the cultures of the enteritidis bacilli reacted to a certain extent to the serum of the first rabbit (immunized against B. Gaertner), but in the higher dilutions it was shown that the Aertrycke serum had a much greater effect. In the same way the Aertrycke culture itself gave a moderate reaction with the Gaertner serum, and a complete reaction with the Aertrycke serum, in a dilution of 1 in 1,000 .

These results, together with the previously-mentioned cultural reactions, indicate that 18 of the 20 cultures examined belong to the Aertrycke, or Breslaviensis, species of the enteritidis group. The remaining two cultures of this group from the small intestine of $\mathrm{a}$ pig and from the small intestine of a child, were found to react equally well either to the Gaertner or to the Aertrycke serum, even in a dilution of $I$ in 100,000 . This peculiarity was also observed in the B. psittacosis, pointing to the conclusion that these two cultures were nearly allied to that bacillus. It will be noticed that the ro cultures of the Paratyphoid A group gave no reaction with the three serums above mentioned. A fourth rabbit was therefore immunized with a culture of $B$. paratyphoid A of Schottmüller, and each of these cultures tested against the serum. None of the ten cultures, however, gave any reaction, thus giving no reaction at all with the four serums experimented with. It is certain that, according to their cultural reactions, they belong to the Paratyphoid A group, but in their serum reactions they do not agree with two known cultures of the group-Schottmüller's Paratyphoid A and the paratyphoid of Brion and Kayser. They belong possibly to yet another species of the same group.

The agglutination tests furnish one of the best laboratory methods of classifying the different organisms, and are much more delicate than the cultural methods, as is shown in the case of the four organisms of the hog-cholera group "Maryland," "Arkansas" of Theobald Smith, Evans's bacillus, and McFadjean's bacillus, which all differ in their cultural reactions, but, as will be seen on reference to the table, react equally well to the Aertrycke serum. The agglutination reaction, however. does not necessarily indicate the specific virulence for different animals, the $B$. of mouse typhoid, for example, giving the same agglutinative reaction as the $B$. enteritidis of Gaertner, although the virulence of the mouse typhoid bacillus is, so far as we know, confined to mice and rats. The hog-cholera bacillus of McFadyean is virulent for pigs, but not for guinea-pigs. This speclfic virulence may possibly be acquired by passage through certain definite animals, but this is a matter for further research.

It will be observed that the cultures of the enteritidis group isolated from animals' intestines agree in agglutination reactions with the hog-cholera bacilli, as they are both agglutinated with Aertrycke serum; they also agree culturally with the hog-cholera bacilli of Evans, and "Maryland" of Theobald Smith.

It was decided to test, therefore, whether these bacilli from animals' intestines could produce hog cholera in the pig. A broth culture of bacilli of the Aertrycke type isolated from the large intestine of a pig being selected, $500 \mathrm{c.cm}$. of this culture, mixed with milk, was given to a young pig 4 months old, that being the most susceptible age. The animal, however, did not contract hog cholera. A second feeding experiment was tried with another young pig, a litre of a forty-eight hours' broth culture being administered. This produced violent diarrhoea and loss of appetite on the following day, which passed off in thirty-six hours, but on the animal being killed a week later no trace of the lesions peculiar to hog cholera was found in the intestines. The post-mortem examination was kindly performed by Professor McFadyean, of the Royal Veterinary College. The violent diarrhoea in the second feeding experiment seems a further proof of the relationship of these bacilli with those of the food-poisoning group.

Grenkral Conclusions.

I. There exist in the intestines of healthy animals organisms conforming morphologically and biologically to the enteritidis and Paratyphoid A types.

2. These organisms, as regards their agglutination reactions, fall into the following groups:

x. B. enteritidis, Aertrycke, or hog-cholera type.

2. B. enteritidis, psittacosis type.

3. B. paratyphoid A, unknown typo.

3. The nomenclature adopted by different observers is uneatisfactory, but is based on the principal differentiating eriterion we at present possess-namely, specific virulence.

My best thanks are due to Dr. Allan Macfadjen for many valuable suggestions during this research.
1 Ostertag, Handbuch der Fleischbeschau, 1904. 2 Van Ermengem, Handbuch der pathogenen Afikro-organismen (Kolleand Wassermann), vol. ii, p. 637 Gaertner, Breslauer aerztlich. Zeit., Nos 21 and 22, 1883. 4 Achard and Bensaude, Bull. et Mém. de la Soc. de Méd. des Hôpitaux. November 27 th. 1896. 5 Libman, Journ. of Med. Research, vol. visi, p. 168 . 1902. 6 Nocard and Leclainche. Les Maladies Microbiennes, 1893. 'T Loeffler. Centralbl. fïr Bakt., vol xi, p. 129: Theobald 8mith, Bureau of Animal Industry, Bull No. 6, Washington, 1893 ; Schottmüller, Zetfs. $f$. Hygiene, vol. $\times \times \times 71 . p .368$, rgor. 8 Brion and Kayser, Münch. med. Woch., No. 15. 1902.9 Fischer, Zeits. f. Hygiene, vol. Xxxix, p 447, 1902. Jo Ford, Studies from the Rockefeller Institnite, vol. ii. 1904. il jurham, BRITISH MEDICAL JodkNAL, December rith, r\&g8. 'j2 Durham, BRITISH MEDICAL JouRNAL, September 3rd, 1898. is Irautmann, Zeits. f. Hygiene, vol. xlv, p. 139, 1903.

\section{SPIROCHAETAE IN SYPHILIS.}

Bx E. J. McWEENEY, M.A., M.D., D.P.H., F.R.C.P.I., Professor of Bacteriology and Pathology, C.U. Medical Ecbool, Dublin, Bacteriologist to the Local Goverument Board for Ireland.

In the number of the German Imperial Health Office Publications just issued, ${ }^{1}$ Schaudinn and Hoffmann have a paper (dated April roth) describing organisms of Spirochaetae type which they find constantly present in syphilitic lesions. Of these Spirochaetae they distinguish two sorts, one larger, thicker, and more readily stained, the other smaller, thinner, and taking up dyes with difficulty. The former they find mainly in cases of condyloma acuminatum; the latter they find exclusively in genuine syphilitic chancres and efflorescences, not only on the surface of the primary sore but also on its deeper aspect (laid bare by excising it). They also find this organism in the secretion of the so-called "mucous tubercles," and in the depth of indolent buboes. This very slender, delicate, stain-resisting organism is provisionally named by Schaudinn, Spirochaete pallida.

Through the courtesy of Dr. Pagin Meldon, Surgeon to the Westmorland Lock Hospital, Dublin, I have been placed in a position to verify Schaudinn's statements, and in view of the extreme theoretical and practical importance of any clue to the hitherto mysterious question as to the causation of spphilis, I think it right to at once communicate the results I havehitherto obtained. I may say at once that in every one of the 9 cases of undoubted syphilis in the primary and secondary stage which I have examined, spirochaetae were readily demonstrable. In a case of advanced tertiary ulceration of the palate I failed to find the spirochaete, and I also missed it in a case of muco purulent vaginitis, unaccompanied by ulceration and considered by the medical attendant (Dr. Meldon) not to be of syphilitic nature. Admittedly the number of non-syphilitic control cases examined is far too small but this objection I hope to speedily meet. It is accounted for by lack of timefor more extensive examinations.

Method.

The patient (hitherto I have only examined adult females) having taken her position in the examination-chair, thin filmpreparations were made on slides from the secretion of any sores, etc. In a few of the cases a trace of the material was suspended in sterile broth, and put up as a hanging-drop, when the movements of the spirochaetae could readily be observed. The dried films were (in accordance with the suggestion of Schaudinn) fixed in absolute alcohol for ten minute; and stained for geveral hours (usually till next day), in very strong Giemsa stain ${ }^{2}$ (Giemsa's azur I azur Ir eosin, dissolved in methyl-alcohol and neutral glycerine, 3 drops of the compound to the c.cm. of water). The highest powers are required on account of the tenuity of the object and its weak staining affinity. I used an oil immersion $\frac{1}{2} \mathrm{t}$ th of Leitz.

\section{Description of Spirochaetae Found.}

Spirally twisted, extremely delicate organisms, actively motile, with peculiar corkecrew movement in either direction. Length from 7 to about $18 \mu$, averaging about $12 \mu$. Thickness too small to measure. Some were equally thick throughout; others, more especially the longer ones, were decidedly thicker in the middle, and tapered, slowly at first, afterwards more rapidly, towards the ends. The coils were often seven or eight in number, not regularly spiral, more open towards the extremities. sometimes nearly effaced. The smaller spirochaetae looked like detached flagella of the typhoid bacillus in a Pitfield preparation.

As regards structure, with the magnification at my disposal, I could make out no more than a granular appearance, more highly alternating with less highly refractive dots, in the fresh preparation. In certain specimens I convinced myself that nearer to one end lay a granule larger than the others and 
projecting from the sides of the organism (? a nucleas or blepharoplast). In certain other specimens an excessively thin line seemed to fringe the concavity of some of the roils, and to suggest a trace of an undulating membrane. The se may have been double forms (see lower $d j w n$ ).

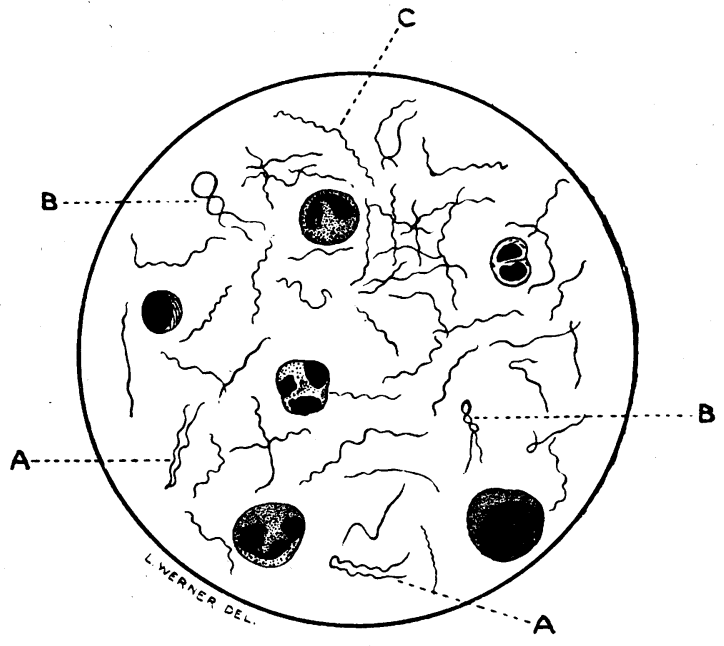

Fig. 1.--8ecretion of condyloma from Case I (3., aged 20). The divisions are those of the stage micrometer viewed with the same power: each $=0.01 \mathrm{~mm}$. The number of spirochaetae is reduced, and special forms found in other preparations are sketched in ; $\Delta A$, parallel forms joined at one end; $B$, forms joined at one end, but crossing (cf. Schaudinn's fig., loc. cit ); c, double-length. end-to-end form. There is another such individual below the centre of the field.

\section{Staining Reaction.}

Gram, negative. Carbol-fuchsin, acting for an hour undiluted, gave poor results on the only occasion I tried it. The best results were obtained with the Giemsa mixture, which imparted to the spirochaetae a distinctly reddish-violet tinge, similar to that of the neighbouring leucocytic nuclei (the Romanowsky chromatin stain), whilst the bacteria in the preparation came out blue. From this behaviour, I would infer that the spirochaetae are composed of "chromatin." I did not observe the above-mentioned granule in stained specimens.

\section{Reproduction.}

Hitherto, attempts at artificial culture of pathogenic spirochaetae-for example, those of relapsing fever and angina Vincenti-have failed, owing to the special precautions necessitated by the protozoal nature of these parasites having been ignored. None of the material that has hitherto passed through my hands was sufficiently free from bacteria for attempts at culture on human-blood-agar, and I accordingly made no trials in this direction. In several of the stained preparations made (especially from Cases $I$ and VI) there were forms to be seen which agreed closely with those figured by Schaudinn ${ }^{3}$ in his description of the reproduction of his Sp. Ziemanni. Thus, I saw pairs of individuals lying close together and almost parallel, but united at one end (A). At the first glance the pair might have readily been mistaken for a trypanosome Again, some of the longer forms presented a gap or unstained spot exactly in the centre, as though composed of two individuals that had been united end to end and were in the act of coming apart.

Relation to Cells.

The spirochaetae were extra-cellular. In the fresh state they were often attached to the pus cells by one end and caused them to sway to and fro, or even dragged the cells along a little way by their vigorous movements. The end of the organism was sometimes seen to be completely buried in the cell protoplasm. Both ends of the spirochaetae were sometimes attached to cells.

Cases.

CASE 1.-3., aged 22. Large condyloma of right labium. Mucous tubercles on surrounding skin. This, the first case examined, produced a deep impression owing to the unusual character of the microscopic picture. The secretion from the interpapillary recesses of the conpicture. The secretion from the interpapillary recesses of the conembedded in a tangle of these organisms, of which many millions must havo been present in each slide film. Large, distinctly-staining form predominated, but the thinnest, palest sorts were readily found on care ful search. Here and there were agglomerations, but I failed to trace a radial or any definite arrangement. The moisture on the surface of the mucous tubercles also contained spirochaetae in smaller numbers and of smaller size than those of the condyloma. This patient had received several subcutaneous injections of mercury.

CASE Ir.-F. Typical mucous tubercle of buccal mucosa. The scrapings contained small pale spirochaetae in relatively small number, and hard to see uwing to their tenuity.

CASE III-C. Mucous tubercle of left labium, and a sore which might be the remains of the primary chancre. Spirochaetae numerous, small, pale, in both lesions.

CASE IV.-M. Condyloma of left labium. Same result.

CASE v.-O'G. Same lesion. Same result.

CASE VI.-L. L. Early secondaries. Remains of primary sore on left labium, which was greatly tumefied. Secretion on surface of sore swarming with bacteria, amongst which were many pale, unevenlycoiled spirochaetae, some of which presented a typical end-to-end appearance.

CASE VIr.-B. This girl had ulcers, pápules, and condylomata on the genitals, as well as an enormous suppurating left inguinal bubo, which had burst just previous to examination. The pus seemed sterile, and the most careful examination failed to detect spirochaetae. The secretion from the sore, however, was found to be swarming with the organism, some of the individuals being very long $(18 \mu($ ?) a double form).

CASE vIII.-N. Sore on genitals, abundant leucorrhoeal discharge, crusts somewhat like rupia over back and chest. The pus obtained by raising one of the crusts proved to contain streptococci and staphylococel, also diphtheria-like bacilli in "Chinese-letter" groups, but spirochaetae were absent. In the vaginal secretion and the exudate covering the ulcer on the labium were many large stiff-looking segmented bacilli like anthrax, smaller bacilli, and numerous spirochaetae, some agglomerated in clumps, the components of which were very small and faint]y stained, so that the arrangement could not be definitely ascertained.

CASE IX. $-\mathrm{N}-\mathrm{n}$. Sore on genitals; spirochaetae numerous.

CASE X.-B-1. Tertiaries; very extensive destruction of palate. spirochaetae could not be found in the secretion covering the ulcer

CASE XI.- I- - t. Abundant vaginal discharge not regarded as gyphilttic; no sore; ? gonorrhoea (gonocoscus not observed in my preparation). Spirochaetae not found.

\section{Concluding Remarks.}

1. A species of spirochaete has lately been shown by Schaudinn (loc. cit.) to be a stage in the life-history of a trypanosome (T. Ziemanni) of the stone-owl. This raises the question whether all spirochaetae-for example, those of relapsing fever, pseudo-diphtheritic angina, and of tropical spirillosis (to which the lamented death of Dutton was due) -are also protozoa, and mere stages in the life-history of flagellates.

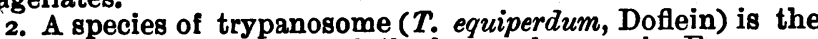
cause of a sexual disease of the horse-known in France as mal de coit, or dourine. This malady is not unlike syphilis in some of its manifestations (oedema of genitals, cutaneous plaques, and subsequent degeneration of the spinal cord). ${ }^{4}$

3. Although trypanosomes are, as a rule, conveyed by an invertebrate intermediate host, such as the blood-sucking flies, Glossina and Stomoxys, this need not be the case. The trypanosome of dourine is conveyed from stallion to broodmare by direct contact, and can even pass the unbroken mucosa, as was first shown by Rouget. ${ }^{\circ}$

4. Kala-azar, a disease due to Leishman-Donovan bodies, which are almost certainly a stage in the life-history of a trypanosome, has, even as I write these lines, been shown by Leonard Rogers ${ }^{B}$ to be propagated by sexual cohabitation.

5. Metchnikoff has found spirochaetae in the syphilitic 5. The above considerations would seem to render it not at all improbable that the spirochaete may be etiologically connected with syphilis. It would, therefore, be most important to make careful search for it in deeply-situate lesions beyond the reach of surface contamination, and to establish its absence in non-syphilitic ulcers of the genital tract. Possibly the tertiary and congenital forms of the disease may prove to be chronic intoxications, due to the metabolic products of the spirochaete. I desire. in conclusion, to express my deep sense of gratitude to Dr. Pugin Meldon for the material he 80 kindly placed at my disposal ; to Dr. Gray, house-surgeon at the I.ock Hospital, for all the help he gave me, and to my colleague, Dr. Werner, for the accompanying sketch he was good enough to make from one of : $m y$ preparations (Case I).

\section{REFERENCES}

1 Arb. ars dem kaiserl. Gesundheitsamte, Bd. 22. ${ }^{2}$ Centralbl. f. Bakt., 1904 p. 308. 3 Arb. a. $d$. k. Ges., Bd. 20. I903. "For the best account of this Masson, 1904. Chapter X. 5 Loc. cit., p. 283. 6 Lancet, June 3 rd, 1905. 